\title{
Microstructure Features of Ternary Alkali-activated Binder Based on Tungsten Mining Waste, Slag and Metakaolin
}

\section{Naim Sedira and João Castro-Gomes}

Centre of Materials and Building Technologies (C-MADE/UBI), Department of Civil Engineering and Architecture, University of Beira Interior (UBI), 6201-001 Covilhã, Portugal

\section{Abstract}

This study determines the effect of ground granulated blast furnace slag (GGBFS) and metakaolin (MK) on the microstructural properties of the tungsten mining waste-based alkali-activated binder (TMWM). During this investigation, TMWM was partially replaced with $10 \mathrm{wt} . \%$ GGBFS and $10 \mathrm{wt} . \% \mathrm{MK}$ to improve the microstructure of the binder. In order to understand the effect of the substitutions on the microstructure, two pastes were produced to make a comparative study between the sample contain 100\% TMWM and the ternary precursors. Both precursors were activated using a combination of

Corresponding Author:

Naim Sedira

sedira.naim@ubi.pt

Received: 20 March 2020

Accepted: 30 April 2020

Published: 13 April 2020

Publishing services provided by Knowledge E

(c) Naim Sedira and João Castro-Gomes. This article is distributed under the terms of the Creative Commons

Attribution License, which permits unrestricted use and redistribution provided that the original author and source are credited.

Selection and Peer-review under the responsibility of the RICON19 - REMINE International Conference Conference Committee.

\section{G OPEN ACCESS} alkaline activator solutions (sodium silicate and sodium hydroxide) with the ratio of 1:3 (66.6 wt.\% sodium silicate combined with 33.33 wt.\% of $\mathrm{NaOH} 8 \mathrm{M}$ ). The alkali-activated mixes were cured in oven at temperature of $60{ }^{\circ} \mathrm{C}$ in the first day and at room temperature for the next 27 days. The reaction products $\mathrm{N}-\mathrm{A}-\mathrm{S}-\mathrm{H}$ gel and (N,M)-A-S-H gel resulted from the alkaline activation reaction process. In addition, a formation of natrite $\left(\mathrm{Na}_{2} \mathrm{CO}_{3}\right)$ with needles shape occurred as a reaction product of the fluorescence phenomena. However, a dense matrix resulted from the alkline activation of the ternary precursors containg different gels such as N-A-S-H, C-A-S-H and (N,M)-C-A-S-H gel, these results were obtained through SEM-EDS analyses, as well FTIR tests.

Keywords: Mining Waste, Alkali-activated, Microstructure, Slag, Metakaolin

\section{Introduction}

The world nowadays facing a challenge to find solutions for the mitigation of waste accumulation on landfills and global warming increase. Recently, new clean technologies are applied as a potential solutions to mitigate global environmental threats by reusing the pollutant materials and sequestrate industrial waste and greenhouse gases [1]. The valorisation and re-using of some waste minerals to produce a new cementitious materials using the alkaline activation process technology by blend the precursors (minerals waste) with the alkaline activator solutions is one of the solution that allow to re-use such waste [2]. Those mineral waste are alumino-silicate rich materials (such 
as mining waste [3], brick powder waste [4] and fly ash [5]) and others supplementary cementing materials such as by-products waste (Slags: like electric arc furnace slag [6] and GGBFS [7]). Moreover, some studies were using metakaolin (MK) which has been largely investigated for many years in the production of geopolymers due to its high reactivity and the homogeneous reaction products that formed after the geopolymerization[8]. Those materials are able to form a different reaction products such as: N-A-S-H, C-A-S-H and their hybrid (N,C)-A-S-H gels depend to the type of the precursors and the activator solutions used. The main alkaline activation product resulting from TMWM activation is N-A-S-H type gel. However, when TMWM blended with other waste such as glass waste powder formed more (C, N)-A-S-H gel. Where the Ca released by WG dissolution is incorporated into the N-A-S-H type gel [9].

The current study aimed to evaluate the feasibility of incorporating amount of GGBFS and MK into TMWM as a source of silica, alumina and calcium to enhance the microstructural properties of the tungsten mining waste based-alkali-activated binder and produce more alkaline activation products. In addition, the addition of GGBFS and MK was to improve the reactivity of the TMWM precursor. The microstructure of the 100\%TMWM$A A B$ and the ternary-AAB (the blending of TMWM, GGBFS, MK and the activator solutions) were investigated using SEM-EDS and FTIR analyses.

\section{Experimental Programme}

\subsection{Materials}

\subsubsection{Precursors}

As received from Panasqueira mine located in Covilhã, Portugal. TMWM was dried in oven at $60{ }^{\circ} \mathrm{C}$ temperature for 24 hours. Afterwards the dried mud was mechanically disaggregated using a crushing machine and sieved under $500 \mu \mathrm{m}$ particle size. The slag used in the current study is a ground granulated blast-furnace slag type derived from the production unit of the cement plant of Ain El Kebira (SCAEK), north-east of Algeria. The slag was grinded and sieved under $63 \mu \mathrm{m}$ in order to use as a cement additive. While GGBFS is a by-product resulting from the separation of the metal from the ore at the metallurgic unit of El Hadjar located in the north-east of Algeria. The metakaolin (METAMAX) high reactivity metakaolin (HRM) with a strength activity index as per ASTM C-1240, supplied by the chemical company BASF Catalysts LLC. 
The particle size distribution curves of milled TMWM, GGBFS and MK are shown in Fig. 1. The powders were determined using laser diffraction (CILAS 1190). The median particle size diameter $\left(D_{50}\right)$ of TMWM, GGBFS and MK were $177.37 \mu \mathrm{m}, 14.83 \mu \mathrm{m}$ and 3.8 $\mu \mathrm{m}$ respectively. Moreover, D10 of TMWM, GGBFS and MK were $8.04 \mu \mathrm{m}, 1.58 \mu \mathrm{m}$ and 1.3 $\mu \mathrm{m}$ respectively, D10 is the diameter at which $10 \%$ of the sample's volume is comprised of particles with a diameter less than this value. In addition, $D_{90}$ is the diameter at which $90 \%$ of the sample's volume is comprised of particles with a diameter less than this value. The $D_{90}$ of $T M W M=398.6 \mu \mathrm{m}, \mathrm{GGBFS}=35.2 \mu \mathrm{m}$ and for $\mathrm{MK}=11.3 \mu \mathrm{m}$.

The chemical compositions of the precursors are shown in Table 1 was determined by Hitachi S-4800 microscope instrument through the EDS (Energy Dispersive X-ray) analysis. The TMWM and MK contains high levels of $\mathrm{SiO}_{2}$ and $\mathrm{Al}_{2} \mathrm{O}_{3}$, however, GGBFS contain high levels of $\mathrm{SiO}_{2}$ and $\mathrm{CaO}$ which are essential for alkali-activation, together with moderate amounts of Mg contain in TMWM and GGBFS.

TABLE 1: Chemical composition of TMWM, GGBFS, MK and the ternary precursors.

\begin{tabular}{l|c|c|c|c|}
\hline Component & TMWM & GGBFS & MK & Ternary Precursor \\
\hline $\mathrm{Al}_{2} \mathrm{O}_{3}$ & 17.05 & 7.79 & 43.2 & 18.74 \\
\hline $\mathrm{SiO}_{2}$ & 46.67 & 34.1 & 51.4 & 45.89 \\
\hline $\mathrm{TiO}_{2}$ & 0.6 & 0.37 & 2.5 & 0.77 \\
\hline $\mathrm{SO}_{3}$ & 7.9 & 1.27 & 0.04 & 6.45 \\
\hline $\mathrm{K}_{2} \mathrm{O}$ & 4.9 & 0.51 & 0.16 & 3.99 \\
\hline $\mathrm{CaO}$ & 0.69 & 48.7 & 0.3 & 5.45 \\
\hline $\mathrm{Fe} \mathrm{O}_{3}$ & 15.47 & 0.4 & 0.51 & 12.47 \\
\hline $\mathrm{MgO}$ & 4.83 & 5.09 & 0.12 & 4.39 \\
\hline $\mathrm{Na}{ }_{2} \mathrm{O}$ & 0.8 & 0.54 & 0.3 & 0.72 \\
\hline $\mathrm{MnO}$ & - & 0.23 & 0.1 & 0.03 \\
\hline $\mathrm{ZnO}$ & 1.09 & - & 0.1 & 0.88 \\
\hline
\end{tabular}

\subsubsection{Alkaline activators}

Two types of alkaline activators were used in the current study, sodium silicate and sodium hydroxide $(\mathrm{NaOH})$.

Sodium silicate (ref. D40) with the chemical composition: (8.60 wt.\% $\mathrm{Na}_{2} \mathrm{O}, 27.79$ wt.\% $\mathrm{SiO}_{2}, 63.19$ wt.\% $\mathrm{H}_{2} \mathrm{O}$, and 0.4 wt.\% $\left.\mathrm{Al}_{2} \mathrm{O}_{3}\right)$ with modulus of silicate $\left(\mathrm{SiO}_{2} / \mathrm{Na}_{2} \mathrm{O}\right)=3.23$, supplied by Solvay SA, Póvoa de Santa Iria, Portugal. 
Sodium hydroxide flakes of $98,6 \%$ purity were supplied by DOS SANTOS, LDA Portugal. Sodium hydroxide solution was prepared by dissolving $\mathrm{NaOH}$ pellets in distilled water to provide concentration of $8 \mathrm{M}$ and allowed to cool $24 \mathrm{~h}$ before use.

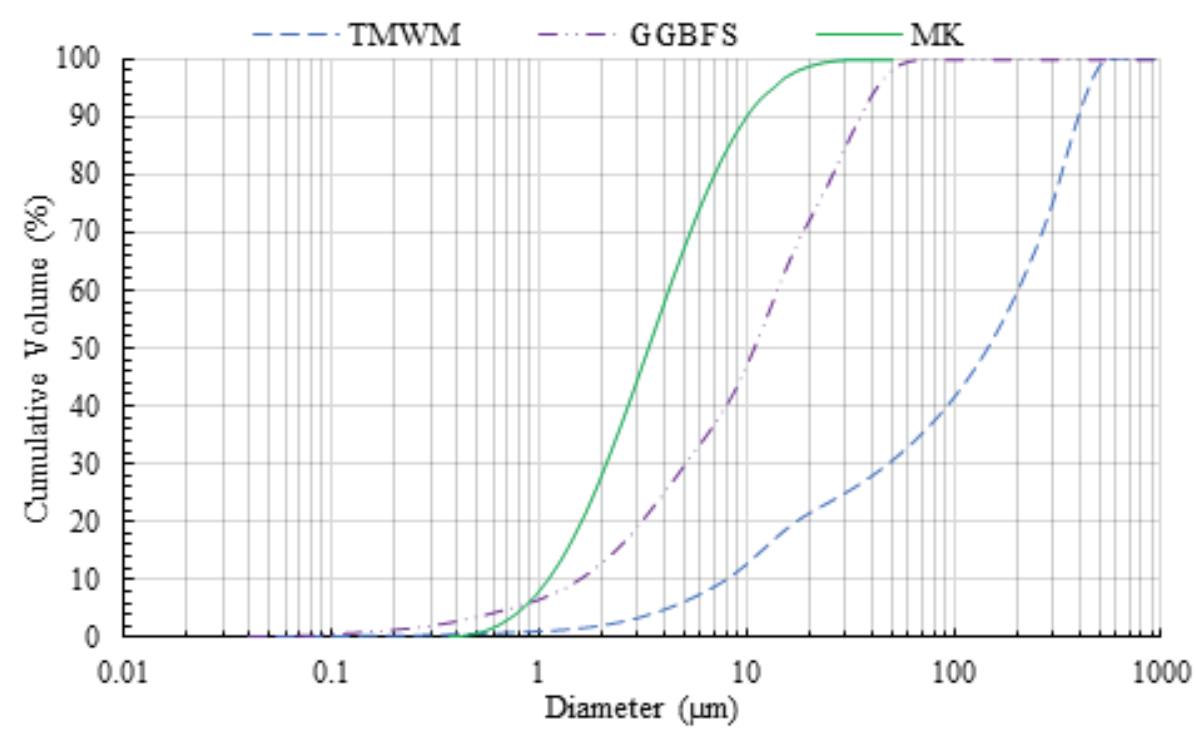

Figure 1: Particle size distribution curves of raw materials (TMWM, GGBFS and MK).

\subsection{Paste preparation and experimental techniques}

Two alkali-activated binders were investigated by blinding the precursors with the alkaline activator solutions. The first precursor was 100\% TMWM however the second precursor was a ternary material (80 wt.\% TMWM + 10 wt.\% GGBFS + 10 wt.\% MK). The ternary precursors were mixed together in a container and agitated to ensure the homogeneity of the material. After that the precursors were activated with 66.6 wt.\% sodium silicate solution + $33.3 \mathrm{wt.} \% 8 \mathrm{M} \mathrm{NaOH}$ with "solid/liquid" ratio of 2.5. The sodium silicate solution was mixed together with $\mathrm{NaOH}$ using Magnetic stirrers "agimatic e selecta" for $5 \mathrm{~min}$. The resulted alkaline activator solution was added to the precursors and mixed by hand between 5-10 min. Then, the pastes were cured in an oven at 60 " $\mathrm{C}$ for $24 \mathrm{~h}$. After the experiment, the samples were removed from the oven and cooled to laboratory temperature. At 28 days of the reaction, the pastes were prepared for the different analyses. The initial ratios [(Si/Al), (Ca/Si), (K/Al), and (Na/Si)] of the mixtures are given in Table 2

For SEM-EDS analyses the samples were examined by a Hitachi S-4800 microscope instrument. The EDS (Energy Dispersive X-ray) analyses were using Bruker Xflash 5010 Cooled by Peltier resolution $\leq 129 \mathrm{eV}$ of $\mathrm{Mn}$ Detector EDS instrument. The specimens were coated with gold. 
TABLE 2: Initial ratios of the mixtures (TMWM-AAB and Ternary-AAB)

\begin{tabular}{|l|c|c|c|c|}
\hline Ratios & Si/Al & Ca/Si & K/Al & Na/Si \\
\hline TMWM-AAB & 2.719 & 0.014 & 0.311 & 0.171 \\
\hline Ternary-AAB & 2.122 & 0.123 & 0.239 & 0.391 \\
\hline
\end{tabular}

Fourier Transform Infrared spectroscopy (FTIR) using the Nicolet iS10 FTIR Spectrometer (Thermo Scientific), Smart iTR accessory instrument in transmittance mode at frequencies $\left(4000-600 \mathrm{~cm}^{-1}\right)$ with diamond HATR crystal. The powders were samples that smashed using marble rod and sieved under $75 \mu \mathrm{m}$ ).

\section{Results and Discussion}

\subsection{SEM-EDS analyses}

The microstructure analyses of the 100\% TMWM and the ternary (TMWM, GGBFS and MK) alkali-activated pastes are shown in Fig. 2 and Fig. 3 respectively. Although the sample ternary-AAB had $80 \mathrm{wt} . \%$ TMWM, the microstructure was different compared to the sample prepared using 100 TMWM. The matrix formation process in TMWM-AAB is different from that seen in the ternary-AAB which results in different reaction products. In all samples (TMWM-AAB and ternary-AAB), gel structure was observed. In general, four major morphological features were observed, crystalline particles (such as quartz or muscovite or illite) with reaction product on the surface [Fig.2a (spot M1)], dense gel phases were it could not be asserted whether in these mixtures coexisted C-A-S-H and N-A-S-H phases or one hybrid (M,C)-A-S-H gel where $\mathrm{M}$ is $\mathrm{Na}$ or $\mathrm{K}$, tabular type particles with no sharp geometric outline (unreacted particles) and sharp geometric needles [Fig. 2 (spot M2)]. In the TMWM-AAB the TMWM particles are well embedded and connected to the matrix, and some particles are partly covered with needle-like phase. The presence of the needles in the TMWM-AAB after the alkaline activation may correspond to the formation of natrite $\left(\mathrm{Na}_{2} \mathrm{CO}_{3}\right)$ needles which are referred to [Fig. 2 spot M3]. These natrite $\left(\mathrm{Na}_{2} \mathrm{CO}_{3}\right)$ needles does not appear in ternary-AAB SEM image, this may caused by the low reactivity of TMWM were the Na content in the mixture remained as unreacted and during the curing time the $\mathrm{Na}$ reacted with the $\mathrm{CO}_{2}$ in the atmosphere and formed $\mathrm{Na}_{2} \mathrm{CO}_{3}$ under the efflorescence phenomena, as it shows in equation (1) and (2).

$$
\begin{gathered}
\mathrm{CO}_{2(g)}+2 \mathrm{OH}_{(a q)}^{-} \rightarrow \mathrm{CO}_{2}^{-3}{ }_{(a q)}+\mathrm{H}_{2} \mathrm{O} \\
2 \mathrm{Na}^{+}{ }_{(a q)}+\mathrm{CO}_{2}^{-3}(\mathrm{aq})+7 \mathrm{H}_{2} \mathrm{O} \rightarrow \mathrm{Na}_{2} \mathrm{CO}_{3} \cdot 7 \mathrm{H}_{2} \mathrm{O}_{(s)}
\end{gathered}
$$


According to Zhang et al [10], this is therefore a partial neutralization for alkaline activation under natural carbonation conditions, as dissolved $\mathrm{CO}_{2}$ acts as an acid and consumes hydroxides. The main reason for efflorescence in these materials is the availability of mobile $\mathrm{Na}^{+}$and $\mathrm{OH}^{-}$, which are remains as unreacted from the alkaline activator solutions. However, in the Ternary-AAB the Na contend in the alkaline activator solution reacted with the precursors (TMWM, GGBF and MK) during the alkaline activation process, then there was no formation of natrite (needles structure) and it does not appear in ternary-AAB SEM image fig. 3b. With addition of $10 \mathrm{wt}$ \% GGBFS and 10 wt. \% MK to the TMWM, the change in microstructure was distinctly evident. In general, the microstructure of the ternary-AAB sample was denser due to increasing formation of almino-silicate reaction products and C-S-H gel. In fig 3.b the unreacted particles were found coated with the reaction product.

Table 3 shows the average content of the main elements ( $\mathrm{Si}, \mathrm{Al}, \mathrm{Na}$, $\mathrm{Ca}$ and $\mathrm{K}$ ) token by SEM-EDS analysis, and their ratios in the reaction products in both alkali-activated mixtures. The values given in this table represent three different EDS spots for each alkali-activated sample as it shown in the SEM images. The differences in the precursors content and the main elements ratios as a function of the blend composition indicated the formation of a new reaction products with different compositions and structures. The ratios in the Table 3 were compared to the ratios set by Puligilla and Mondal [11] to conclude the type of the alkaline activation products that formed were: (M, N)-A-S-H: 0 $<\mathrm{K} / \mathrm{Al}<1.85 ; 0<\mathrm{Ca} / \mathrm{Si}<0.3 ; 0.05<\mathrm{Al} / \mathrm{Si}<0.43$. K-A-S-H: $\mathrm{K} / \mathrm{Al}=0.47 \pm 0.44 ; \mathrm{Ca} / \mathrm{Si}=$ $0.05 \pm 0.03 ; \mathrm{Al} / \mathrm{Si}=0.23 \pm 0.03$

Mainly two types of gel were identified in the tungsten mining waste mud based-alkaliactivated binder, a gel with a high silicon and aluminium content and smaller amounts of sodium, potassium and calcium which the authors believe may be a N-A-S-H gel containing a certain amount of calcium (Ca) or potassium $(\mathrm{K})$ and forming ((M,N)-A-S$H$ [spot M1]). However, based only on EDS analysis results, it could not be asserted whether in these mixtures coexisted C-A-S-H and N-A-S-H phases or one hybrid (M, $\mathrm{N})$-A-S-H gel as reported previously. In the presence of calcium, N-A-S-H gel evolved as follows: N-A-S-H $\rightarrow$ (N, C)-A-S-H $\rightarrow$ C-A-S-H. This last conversion is not complete in these systems because the amount of calcium present is thought to be insufficient [12]. Additionally, [spot M2] shows a high amount of silicon (18.54), aluminium (12.51) and sodium (13.36), with the ratios $\mathrm{Al} / \mathrm{Si}=0.675$ and $\mathrm{Na} / \mathrm{Si}=1.068$ and poor ratios of $\mathrm{Ca} / \mathrm{Si}=$ 0.021 and $\mathrm{K} / \mathrm{Al}=0.048$, which refers to the formation of $\mathrm{N}-\mathrm{A}-\mathrm{S}-\mathrm{H}$ gel in the alkaline activation matrix. The EDS analysis of the needles observed in the SEM image [spot M3], confirmed the high concentration of sodium $\mathrm{Na}^{+}$(53.37 wt.\%) and poor presence 
of reactive elements such as calcium, aluminium and potassium had produced sodium carbonate (Natrite) by atmospheric carbonation. The analysis of the blend ternary-alkaliactivated binder revealed that it contained an amounts of unreacted particles from the precursors (TMWM, Slag and MK) such as quartz with a high silicon (44.7 wt.\%) content and trace of other composite and poor ratios of $\mathrm{Al} / \mathrm{Si}=0.015$ and $\mathrm{Ca} / \mathrm{Si}=0.011$ [spot $\mathrm{T} 1$ ], along with two alkaline activation products with different compositions: a gel with a high silicon and aluminium content and smaller amounts of sodium, potassium and calcium which the authors believe may be a N-A-S-H gel containing a certain amount of calcium and potassium ((M,N)-A-S-H [spot T2]). Another type of reaction product [spot T3] was formed with high content of silicon (25.76), calcium (9.69), aluminium (6.99) and sodium (4.72), and smaller amounts of potassium (0.84) with a high ratios $\mathrm{Na} / \mathrm{Al}(0.675)$ and $\mathrm{Ca} / \mathrm{Si}$ (0.376) were calcium readily displaces $\mathrm{Na}$ by ion exchange potential is envisaged for the surface of the 3D N-A-S-H gels leading to (N,C)-A-S-H gels. It is anticipated that high content of $\mathrm{Ca}$ in GGBFS will be adsorbed preferentially, and Na will only be retained if insufficient $\mathrm{Ca}$ is available [13].
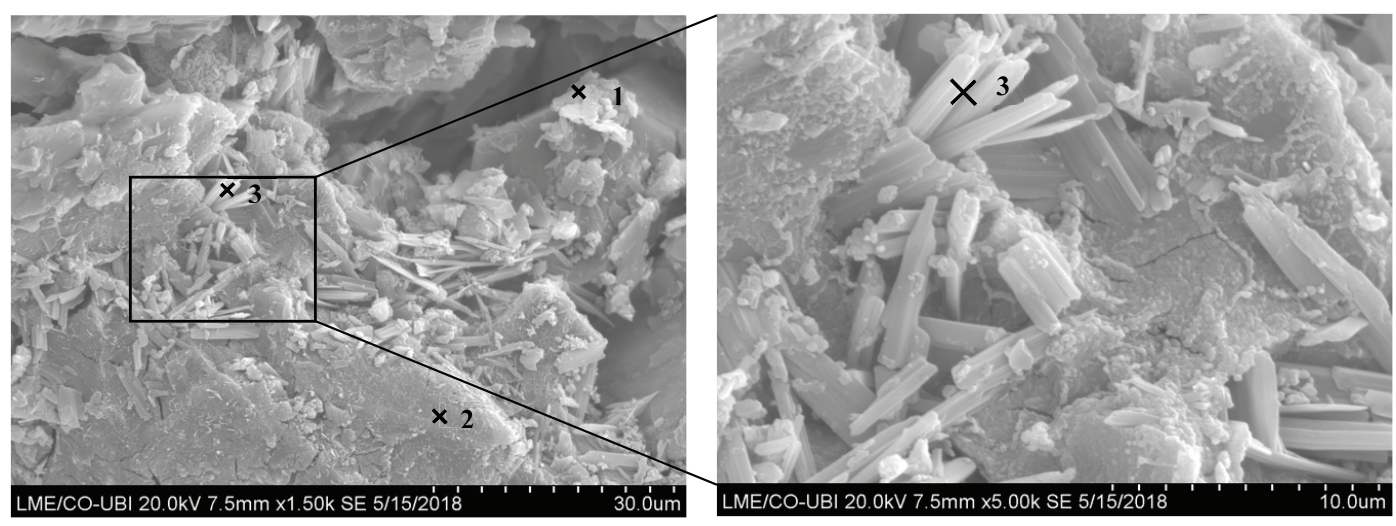

Figure 2: Scanning electron microscope images of the TMWM-based alkali-activated binder.

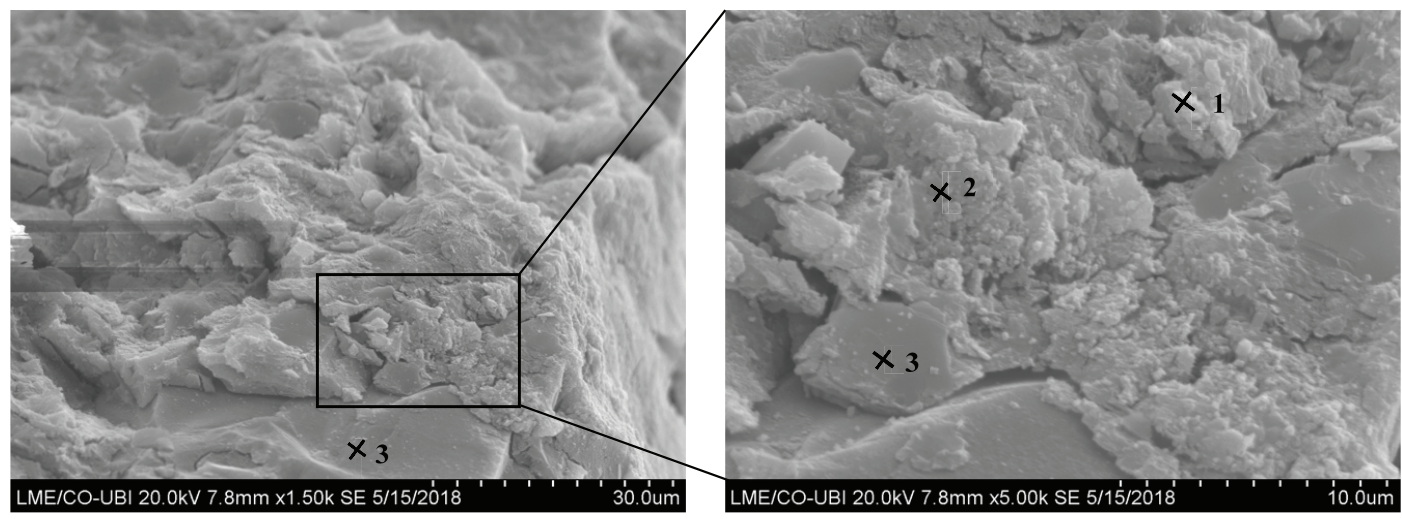

Figure 3: Scanning electron microscope images of the Ternary alkali-activated binder. 
TABLE 3: Element composition and ratios of the TMWM-AAB and Ternary-AAB pastes after the alkaline activation in different spots.

\begin{tabular}{|c|c|c|c|c|c|c|c|c|c|c|c|}
\hline \multirow[t]{2}{*}{ Materials } & \multirow[t]{2}{*}{ Spots } & \multicolumn{5}{|c|}{ Element (wt.\%) } & \multicolumn{4}{|c|}{ Ratios after activation } & \multirow[t]{2}{*}{ Phases } \\
\hline & & Si & $\mathrm{Al}$ & $\mathrm{Na}$ & $\mathrm{Ca}$ & K & $\mathrm{Al} / \mathrm{Si}$ & $\mathrm{Ca} / \mathrm{Si}$ & $\mathrm{K} / \mathrm{Al}$ & $\mathrm{Na} / \mathrm{Al}$ & \\
\hline \multirow[t]{3}{*}{$\begin{array}{l}\text { TMWM- } \\
\text { AAB }\end{array}$} & Spot M1 & 23.27 & 10.67 & 6.6 & 0.42 & 6.19 & 0.459 & 0.018 & 0.580 & 0.619 & $\begin{array}{l}(\mathrm{M}, \mathrm{N})-\mathrm{A}-\mathrm{S}-\mathrm{H} \\
\mathrm{M}=\mathrm{K} \text { or } \mathrm{Ca}\end{array}$ \\
\hline & Spot M2 & 18.54 & 12.51 & 13.36 & 0.39 & 0.6 & 0.675 & 0.021 & 0.048 & 1.068 & N-A-S-H \\
\hline & Spot M3 & 3.27 & 3.02 & 53.37 & 0.14 & 0.62 & 0.924 & 0.043 & 0.205 & 17.672 & Natrite $\left(\mathrm{Na}_{2} \mathrm{CO}_{3}\right)$ \\
\hline \multirow[t]{3}{*}{$\begin{array}{l}\text { Ternary- } \\
\text { AAB }\end{array}$} & Spot T1 & 22.14 & 7.86 & 5.89 & 11.27 & 7.94 & 0.355 & 0.509 & 1.010 & 0.749 & $\begin{array}{c}\text { (M,K)-A-S-H } \\
/ \mathrm{M}=\mathrm{N} \text { or Caand } \\
\text { /or (N, C)-A-S-H }\end{array}$ \\
\hline & Spot T2 & 25.76 & 6.99 & 4.72 & 9.69 & 0.84 & 0.271 & 0.376 & 0.120 & 0.675 & $\begin{array}{c}(\mathrm{N}, \mathrm{C})-\mathrm{A}-\mathrm{S}-\mathrm{H} \\
\text { and/or C-A-S-H }\end{array}$ \\
\hline & Spot T3 & 44.7 & 0.69 & 0.68 & 0.49 & 0.39 & 0.015 & 0.011 & 0.565 & 0.986 & Quartz \\
\hline
\end{tabular}

\subsection{FT-IR analyses}

Fig. 4 shows the FTIR spectra of the two alkali-activated binders, the first binder based on tungsten mining waste as precursor, however the second binder based on ternary (TMWM, GGBFS, MK) precursors. In FT-IR spectra, there was a peak at approximately $3647 \mathrm{~cm}^{-1}$, which was found to be related to $\mathrm{O}-\mathrm{H}$ stretching vibrations. Besides, this peak at the raw TMWM due to the presence of muscovite. In addition, there is broadband in the region of $3215-3353 \mathrm{~cm}^{-1}$ and a peak $1648 \mathrm{~cm}^{-1}$ refer to the spectrum of bending $\mathrm{H}-\mathrm{O}-\mathrm{H}$ vibrations and stretching $\mathrm{O}-\mathrm{H}$ groups respectively[14]. These wavenumbers correspond the weakly bound water molecules which were adsorbed on the surface or trapped in the large cavities between the rings of the alkaline activation products. This bands were disappeared in the raw precursors (TMWM, GGBFS and $\mathrm{MK}$ ) due to the absence of activation products in the raw materials before the alkaline activation process, and it belongs to the reaction products. Whereas a sharp peak centred approximately $2980 \mathrm{~cm}^{-1}$ associated to the $\mathrm{O}-\mathrm{H}$ stretching vibrations of bound water [15]. The stretching vibration of O-C-O bond at approximately $1450-1410 \mathrm{~cm}^{-1}$ indicate the presence of carbonate mineral which having occurred by the atmospheric carbonation, and the coexist of calcite $\left(\mathrm{CaCO}_{3}\right)$ as unreacted particles from GGBFS. Moreover, the presence of natrite $\left(\mathrm{Na}_{2} \mathrm{CO}_{3}\right)$ may due to the carbonation of the large amounts of $\mathrm{Na}$ carried to the surface. The peaks of TMWM-AAB and ternary-AAB show the same peaks intensity even though ternary-AAB sample contains $10 \mathrm{wt} . \%$ of GGBFS that has calcite. Then the TMWM-AAB formed more sodium carbonate due to the unreacted sodium content in the mixture then the unreacted sodium formed sodium carbonate with $\mathrm{CO}_{2}$ of the atmosphere. which is seen before in the SEM 
image corresponding to TMWM-AAB (Fig 2). In addition, a broad band at wavenumber $1436 \mathrm{~cm}^{-1}$ appeared only in the TMWM-AAB which correspond to sodium carbonate $\mathrm{Na}_{2} \mathrm{CO}_{3}$ (Natrite) [16],and disappeared in the ternary-AAB and the starting materials means that natrite $\left(\mathrm{Na}_{2} \mathrm{CO}_{3}\right)$ formed only in TMWM-AAB after the alkaline activation. However, the ternary-AAB that does not show this band means that no natrite are formed and all the soluble sodium contains in the activator are reacted with the precursors. This explain why the natrite needles appears in the SEM images of TMWM-AAB and disappeared in the SEM images of T-AAB (SEM-EDS section). The intensity of the bands at wavenumbers $1245-1249 \mathrm{~cm}^{-1}$ and at wavenumber $1073 \mathrm{~cm}^{-1}$ attributed to the length as well as the angle of the $\mathrm{Si}-\mathrm{O}$ and $\mathrm{Al}-\mathrm{O}$ bonds in the silicates and $\mathrm{MK}$, in this case being sodium alumino-silicate (N-A-S-H) and/or calcium alumino-silicate (C-A$\mathrm{S}-\mathrm{H}$ ) and probably other XRD-amorphous silicate phases [17]. A wide and intense band appears from wavenumber $950 \mathrm{~cm}^{-1}$ to $1200 \mathrm{~cm}^{-1}$. The interpretation of this region may be difficult, as bond vibrations of different compounds tend to overlap from the raw precursors and also the samples after the alkaline activation, producing a highly complex spectrum. While in the unreacted TMWM this band appears at wavenumber $982 \mathrm{~cm}^{-1}$. The FTIR spectra for the pastes attributed to the asymmetric stretching vibrations generated by T-O-T bonds (where T is Si or Al) [18]. The band generated by the $\mathrm{SiO}^{4}$ groups in the TMWM slightly shifted from $982 \mathrm{~cm}^{-1}$ to $980 \mathrm{~cm}^{-1}$ for the sample made only by TMWM as precursor. However, the band considerably shifted from $982 \mathrm{~cm}^{-1}$ to 966 for the sample made by the ternary precursors, due to the formation of alumino-silicate gels such as N-A-S-H and C-A-S-H-types gel. More C-A-S-H type of gel formed in the ternary alkali-activated binder, as a result of the alkaline activation process of GGBFS and MK, the Al-O asymmetric stretch band shifts towards lower frequencies at around $966 \mathrm{~cm}^{-1}$ (Ternary-AAB sample), indicating the formation of an alkaline alumino-silicate gel, due to the presence of calcium and reactive alumina and silica in GGBFS and MK respectively. The peak centred at $874 \mathrm{~cm}^{-1}$ correspond to the $\mathrm{C}-\mathrm{O}$ bending vibration confirms the presence of $\mathrm{CaO}$ in the raw GGBFS. The peak at this wavenumber was disappeared after the alkaline activation of the ternary precursors (contains GGBFS in its composition), due to the reaction of $\mathrm{CaO}$ in the system.

The bands at $797 \mathrm{~cm}^{-1}$ and $770 \mathrm{~cm}^{-1}$ are respectively associated to the Si-O and SiO-Si molecular structure vibrations correspond to the presence of quartz in the original TMWM. Although these bands persist after the activation of the precursors, a reduction in the peaks intensities is observed in the sample contains 100\% TMWM, which indicates that the quartz has partially reacted. However, the peaks at the same wavenumber disappeared in the ternary alkali-activated binder spectra which indicates that more 
amount of quartz has been partially reacted compared to TMWM-AAB sample. Moreover, the absorption peak at $694 \mathrm{~cm}^{-1}$ is due to Si-O-Si symmetrical stretching vibrations, which can be associated to the presence of quartz in the raw material TMWM.
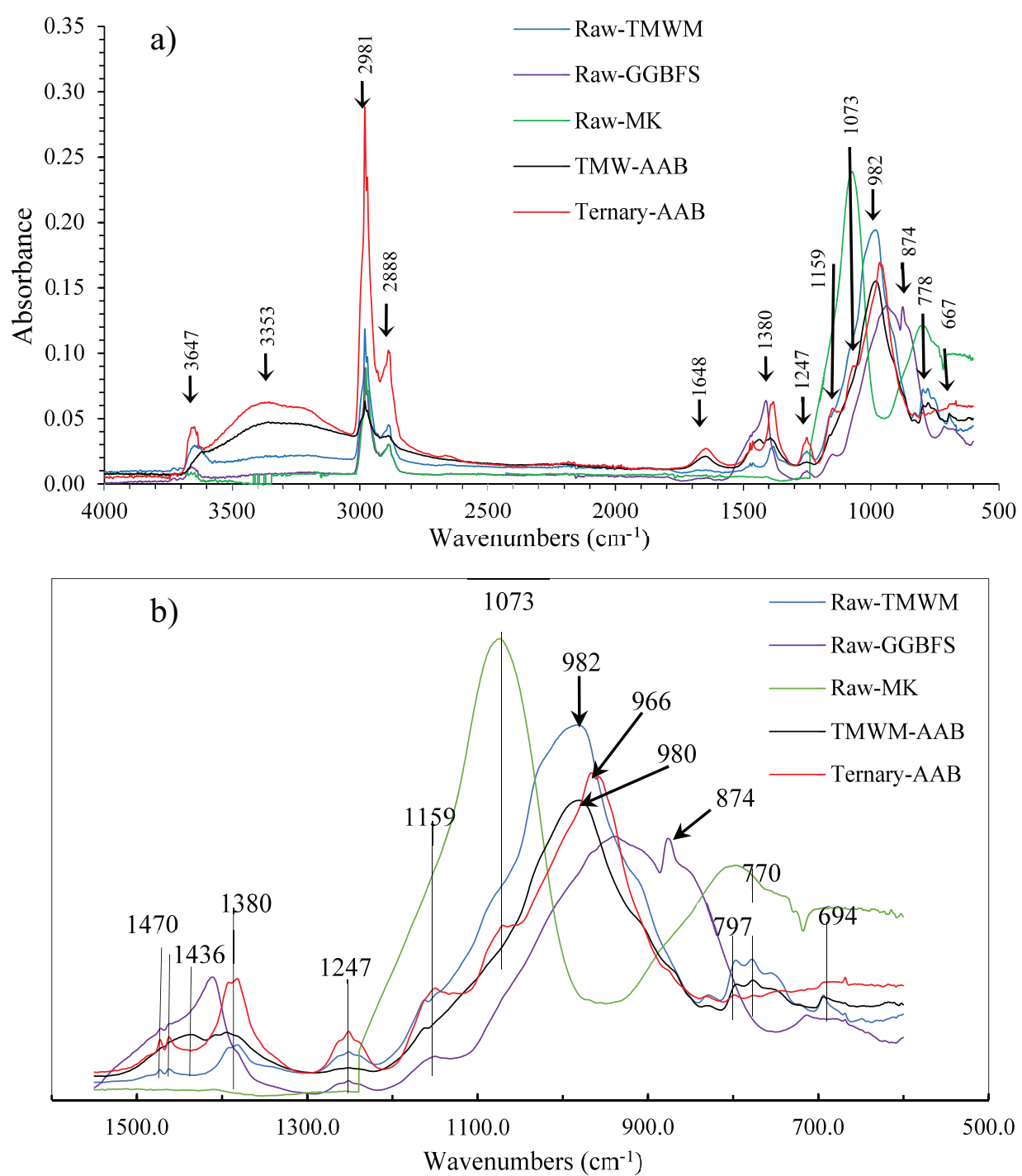

Figure 4: FTIR spectra for the raw TMWM, GGBFS and the samples TMWM-AAB and Ternary-AAB. (a) In the $4000-500 \mathrm{~cm}^{-1}$ range. (b) In the $1500-500 \mathrm{~cm}^{-1}$ range.

\section{Conclusions}

Tungsten mining waste-based alkali-activated binder and ternary (TMWM+GGBFS+MK) alkali-activated binders have been synthesised in order to perform a detailed comparison about their composition and microstructure. these different alkali-activated binders have been studied to highlight differences and similarities in their microstructure. 
Under the conditions of the present study, it appears that addition of GGBFS and MK to the TMWM improved the microstructure properties by forming a homogeneous matrix structure. More specific, the main reaction products obtained in tungsten mining waste mud based-alkali-activated binder were N-A-S-H gel, (M,N)-A-S-H gel and C-S-H, and also the formation of natrite $\left(\mathrm{Na}_{2} \mathrm{CO}_{3}\right)$ needles caused by florescence phenomena. However, complex types of reaction products formed in the ternary-alkali-activated binder such as N-A-S-H gel, C-A-S-H gel, (N,C)-A-S-H gel, (M,N)-A-S-H gel and C-S-H gel. In addition, SEM-EDS and FT-IR analyses confirm the formation of a new product as natrite $\left(\mathrm{Na}_{2} \mathrm{CO}_{3}\right)$ in the TMWM-AAB were it appeared as needles in the SEM image and a spot with high Na content in EDS spot. Additionally, FT-IR spectra shows the stretching vibration of O-C-O which confirm the finding of SEM-EDS analyses about the formation of the natrite in the TMWM-AAB.

\section{Acknowledgements}

This work was partially supported by the Doctoral Incentive Grant BID/ICI-FE/Santander Universidades-UBI/2019 financed by the Santander-Totta bank and the University of Beira Interior.

This work was also partially financed by Portuguese national funds through FCT Foundation for Science and Technology, IP, within the research unit C-MADE, Centre of Materials and Building Technologies (CIVE-Central Covilh a-4082), University of Beira Interior, Portugal.

\section{References}

[1] Humbert P. S. and Castro-Gomes, J. (2019). CO2 activated steel slag-based materials: A review. J. Clean. Prod., vol. 208, pp. 448-457.

[2] Sedira, N., et al. (2017). A review on mineral waste for chemical-activated binders: mineralogical and chemical characteristics. Min. Sci., vol. 24, pp. 29-58.

[3] Pacheco-Torgal, F., Castro-Gomes, J. and Jalali, S. (2009). Tungsten mine waste geopolymeric binder: Preliminary hydration products investigations. Constr. Build. Mater., vol. 23, pp. 200-209.

[4] Sedira, N. and Castro-Gomes, J. (2018). Study of an alkali-activated binder based on tungsten mining mud and brick powder waste. 8th Sci. Conf. Mater. Probl. Civ. Eng., vol. 6002, pp. 1-8. 
[5] Abdalqader, A., Jin, F. and Al-Tabbaa, A. (2015). Development of greener alkaliactivated cement: Utilisation of sodium carbonate for activating slag and fly ash mixtures. J. Clean. Prod., vol. 113, pp. 66-75.

[6] Sedira, N. and Castro-Gomes, J. (2017). Effects of EAF-S on alkali-activation of tungsten mining waste: mechanical properties. in REMINE - International Conference \& Brokerage Event (RICON17) - UBI, Covilha, Portugal, 2017, vol. 1003, pp. 1-6.

[7] Sedira, N. and Castro-Gomes, J. (2018). Strength and microstructure of tungsten mining waste-based hybrid alkaline material: effect of activators. in Proceedings of the 12th fib International PhD Symposium in Civil Engineering, 2018, pp. 145-152.

[8] Bignozzi, M. C., et al. (2013). Mix-design and characterization of alkali activated materials based on metakaolin and ladle slag. Appl. Clay Sci., vol. 73, issue 1, pp. 78-85.

[9] Kastiukas G. and Zhou, X. (2017). Effects of waste glass on alkali-activated tungsten mining waste: composition and mechanical properties. Mater. Struct. Constr., vol. 50.

[10] Zhang, Z., et al. (2014). Fly ash-based geopolymers: The relationship between composition, pore structure and efflorescence. Cem. Concr. Res., vol. 64, pp. 30-41.

[11] Puligilla S. and Mondal, P. (2013). Role of slag in microstructural development and hardening of fly ash-slag geopolymer. Cem. Concr. Res., vol. 43, issue 1, pp. 70-80.

[12] García-Lodeiro I. and Palomo, A. (2013). Variation in hybrid cements over time. Alkaline activation of $\mathrm{fl} y$ ash - portland cement blends. Cem. Concr. Res., vol. 52, pp. 112-122.

[13] Garcla-Lodeiro, I., et al. (2010). Effect of Calcium Additions on N-A-S-H Cementitious Gels. Am. Ceram. Soc., vol. 1940, pp. 1934-1940.

[14] Sedira, N., Castro-Gomes, J. and Magrinho, M. (2018). Red clay brick and tungsten mining waste-based alkali-activated binder: Microstructural and mechanical properties. Constr. Build. Mater., vol. 190, pp. 1034-1048.

[15] Liu, J., et al. (2017). Blast furnace slag obtained from dry granulation method as a component in slag cement. Constr. Build. Mater., vol. 131, pp. 381-387.

[16] Reig, L.et al. (2016). Influence of calcium aluminate cement (CAC) on alkaline activation of red clay brick waste (RCBW). Cem. Concr. Compos., vol. 65, pp. 177-185.

[17] Sedira, N. and Castro-Gomes, J. (2020). Effect of activators on hybrid alkaline binder based on tungsten mining waste and ground granulated blast furnace slag. Constr. Build. Mater., vol. 232, p. 117176.

[18] Garcla-Lodeiro, I., et al. (2008). FTIR study of the sol - gel synthesis of cementitious gels: C - S - H and N-A - S - H. J. Sol-Gel Sci. Technol., pp. 63-72. 